(C) Pharmacotherapy Group, Faculty of Pharmacy, University of Benin, Benin City, Nigeria.

All rights reserved.

Available online at http://www.tjpr.freehosting.net

\title{
Editorial
}

\section{The changing roles of pharmacists in hospital and community pharmacy practice in Nigeria}

The profession and practice of pharmacy did not start in Nigeria as a well defined health care area of specialization as it is today. Rather, pharmaceutical training was borne from the necessity to provide assistance to expatriate medical officers. The genesis of pharmacy practice in Nigeria can be traced back to 1887 when $\mathrm{Dr} R$ Zacchaeus Bailey opened a pharmacy shop for Europeans in Lagos $^{1}$. During the colonial period, those trained to handle drugs were called "dispensers". Such dispensers functioned as dispensers of medicines, sanitary officers, medical aids and anaesthetists in operating theatres ${ }^{2}$. At that time, the development, and hence the role of the pharmacy professional, followed the pattern in other British colonies and was in line with the developments in Britain $^{2}$. The need to import drugs on a large scale, which led to early development of the wholesale drug trade, resulted in additional role for the pharmacists. Since 1960, many develop-ments have taken place in the education, legislations, and practice of pharmacy in various areas including industries, hospitals and communities.

Today, the professional role of the pharmacist in hospitals and community pharmacies is changing from a focus on preparation, dispensing and sale of medications to one in which pharmacists assist the public to get the best possible results from medications through patient education, physician consultation, and patient monitoring. In the 60 s and 70 s, the roles mainly involved the supply and dispensing of medications, bulk compounding (especially of extemporaneous preparations), administrative functions (including care and custody of drugs, drug tendering and purchasing, record keeping and accounting), and staff supervision and management. In the $1980 \mathrm{~s}$, the need to ensure the availability of needed drugs in our hospitals at affordable prices led to the interest of hospital pharmacists in the manufacture of drugs within the hospital system. The introduction and acceptance of clinical pharmacy into the practice of pharmacy in Nigeria in the 1980s led some hospital pharmacists to be involved in clinical activities including drug information service and unit dose dispensing. However, unlike many developed countries, the involvement of pharmacists in Nigeria in the application of the emerging roles has not been impressive. In a survey conducted in 2002 , only $18.2 \%$ of 119 pharmacists practicing in Nigeria stated that they applied most of the 52 suggested practice standards obtained from round one discussion by the Delphi panel of pharmaceutical care experts in their settings $^{3}$. Although pharmaceutical care has become a preferred mode of practice, most pharmacists in Nigeria still hardly offer significant patient-oriented services.

After almost two decades, patient-oriented pharmacy practice in our hospitals and 
community pharmacies has suffered from poor staffing, infrastructure, willingness of the pharmacists to add new evolving roles to their duties, lack of proper coordination of activities, resistance of physicians, lack of proper training for pharmacists, failure of many hospital and community pharmacies to adopt the practice and lack of selfconfidence. These are also frequently compounded by the continuous resistance of some medical doctors against patientoriented pharmaceutical services, particularly in hospital wards.

Pharmaceutical care ${ }^{4}$ is now an acceptable practice to Nigerian pharmacists and the need for its application is frequently addressed in continuing education programmes, conferences and workshops. However, not much has been done by the pharmacy profession to route the practice firmly to avoid neglect and intimidation arising from lack of understanding of purpose and misguided judgment by some other health care professional. The new roles for pharmacists in hospitals and community pharmacies in the provision of pharmaceutical care means that pharmacy profession must begin to address the

- need for the training of more technicians to assist in dispensing functions - if pharmacists will have the time to effectively provide pharmaceutical care; and

- development and enforcement of areas of specialization for pharmacists in hospital and community practice.

The path for continuous growth of the pharmacy profession obviously requires expansion, resurfacing and modernization. This justifies the need for new pharmacy programme and curriculum that can produce the manpower required for the new roles. Thus, the introduction of the Doctor of Pharmacy (PharmD) programme, being pioneered in Nigeria by the University of Benin, Benin City, is a welcome development.

\section{Conclusion}

Pharmacists practicing in Nigeria have many challenges to address that are born of the rapid changes being experienced in health care delivery, particularly, over the last twenty years. With continuing advances in the biomedical area, and in information technology, as well as growing consumer expectations, it can be predicted that this momentum will continue and perhaps accelerate change. In the face of so much innovation and the uncertainty that it brings, it is critical that pharmacists create a forward thinking and flexible vision of the roles that they and other health care professional will play in the evolving health care system.

To survive, pharmacists must be willing to acknowledge the rapidly occurring changes in health care delivery and accept the reality that the changes will continue. Traditional roles and activities which are no longer needed or valued in the new system must be willingly let go. Pharmacists will be continuously left behind unless they aggressively step into action and become involved in all critical activities that are underway in the system or practice arena in which they find themselves.

\section{Patrick O Erah Editor}

\section{References}

1. Adenika FB. Pharmacy in Nigeria. Panpharm Ltd, Lagos, Nigeria, 1998.

2. Daily Times (Nigeria), 8 Jan 1975.

3. Erah PO, Nwazuoke JC. Identification of Standards for Pharmaceutical Care in Benin City. Trop J Pharm Res. 2002; 1 (2): 55-66

4. Hepler CD, Strand LM. Opportunities and responsibilities in pharmaceutical care. $A m \mathrm{~J}$ Pharm Educ 1989;53(Suppl):7S-14S. 